\title{
Case report of Pilomyxoid astrocytoma of the thoracic spinal cord: Literature review with presenting an extremely rare Case of over 70 year's old patient
}

\author{
Zeyad Abousabie ${ }^{1}$, Mohamed Almzeogi ${ }^{2}$, aleksandar janicijevic ${ }^{3}$, and Goran Tasic ${ }^{3}$ \\ ${ }^{1}$ Klinicki centar Srbije \\ ${ }^{2}$ Affiliation not available \\ ${ }^{3}$ klinicki centar srbije klinika za neurohirurgiju
}

March 19, 2021

\begin{abstract}
Case summary: The MRI of a 73 year old male patient with paraparesis, showed an intramedullary mass at the thoracic spinal cord extending from T6 to T8. Partial surgical removal was preformed and a biopsy was taken, followed by postoperative radiotherapy.
\end{abstract}

Case report of Pilomyxoid astrocytoma of the thoracic spinal cord:

Literature review with presenting an extremely rare Case of over 70 year's old patient

Almzeogi.A.Mohamed, Abousabie.A.Zeyad, Janicijevic.M.Aleksandar, Tasic.Goran

Clinic of Neurosurgery, Clinical center Serbia. Zeyad Ali Salem Abousabie . Email : ziad.znati@gmail.com. , Mobile: +381 Mohamed Abdulbaset Almzeogi . Email : Mohamed.almzeogi89@gmail.com, Mobile: +381 69677314

\section{Background}

Pilomyxoid astrocytoma of the spinal cord in adults (PMA) is a rare neoplasm without definitive grade assignment in the revised WHO 2016 classification of tumors in the central nervous system. We report here a case of an adult patient with a spinal intramedullary T6-T8 PMA, its clinical manifestation and managment outcomes.

Case summary: The MRI of a 73 year old male patient with paraparesis, showed an intramedullary mass at the thoracic spinal cord extending from T6 to T8. Partial surgical removal was preformed and a biopsy was taken, followed by postoperative radiotherapy.

Methods: Only a few adult cases of spinal PMA have been reported. Relevant papers were selected for the literature review.

Objective: Our case shows that thoracic PMA spinal cord tumors can occur in elderly age, even though, PMA is a predominantly pediatric tumor, where it has been reported for the first time 20 years ago.

Conclusion: Because of its extremely rare occurrence, especially in this age group, there is a need for treatment guidelines that take into consideration the tumor features and occurrence in old age.

Keywords : Case report, pilomyxoid astrocytoma, thoracic spinal cord, elderly. 


\section{Introduction}

PMA is a rare tumor in adults, and most certainly it is extremely rare in the spinal cord .It was first reported in a pediatric group of patients [1].It has been added under pilocytic astrocytoma PA subtype according to WHO CNS tumor classification in 2007 as grade II, with variant histological characteristics and a more aggressive behavior [2]. PMA predominantly occurs in infants and young children and is most commonly located in the hypothalamic/chiasmatic region and shares other locations with pilocytic astrocytoma like the thalamus, temporal lobe, brain stem and cerebellum [3].

\section{Case}

A 73-year-old male patient with a two month history of sudden onset numbness, gradual weakness in the lower extremities accompanied by walking difficulty was examined. 10 days before admission his symptoms progressed to paraparesis. Magnetic resonance imaging (MRI) showed an intramedullary mass of $73 \times 9 \times 8 \mathrm{~mm}$ at the thoracic spinal cord extending from T6 to T8. On T1 weighted images hypointense intramedullary lesion. T2w weighted images showed hyperintense lesion, signal intensity higher than cerebrospinal fluid.

The patient was transferred from a primary healthcare facility with a past medical history of controlled hypertension and DM II. History of chronic pelvic pain syndrome was reported. Any evidence of prostate cancer or other primary systemic tumors were excluded. Moreover, there was no evidence of any other spinal or intracranial lesion. LP was negative for malignant cells.

He underwent unilateral T7 Hemilaminectomy through posterior approach. Intraoperatively the tumor appeared noncystic and gelatinous. Partial surgical resection was performed, as well as a biopsy was taken for pathological analysis. A histopathological laboratory disclosed that the tumour tissue consisted of bipolar cells with tendency of perivascullar arrangement, embeded in myxoid matrix, Rosenthal fibers were not found. On immunohistochemistry, tumour cells were positive for S-100, GFAP, OLIG2, SOX10 and focally for Synaptophysin. Tumour cells were negativne for panCK (AE1/AE3) and EMA. Mitoses were rare. Proliferative Ki-67 index ranged up to $4 \%$.[figure 1\&2].

After surgery the patient had no improvement. He was refered to recieve external beam radiation therapy

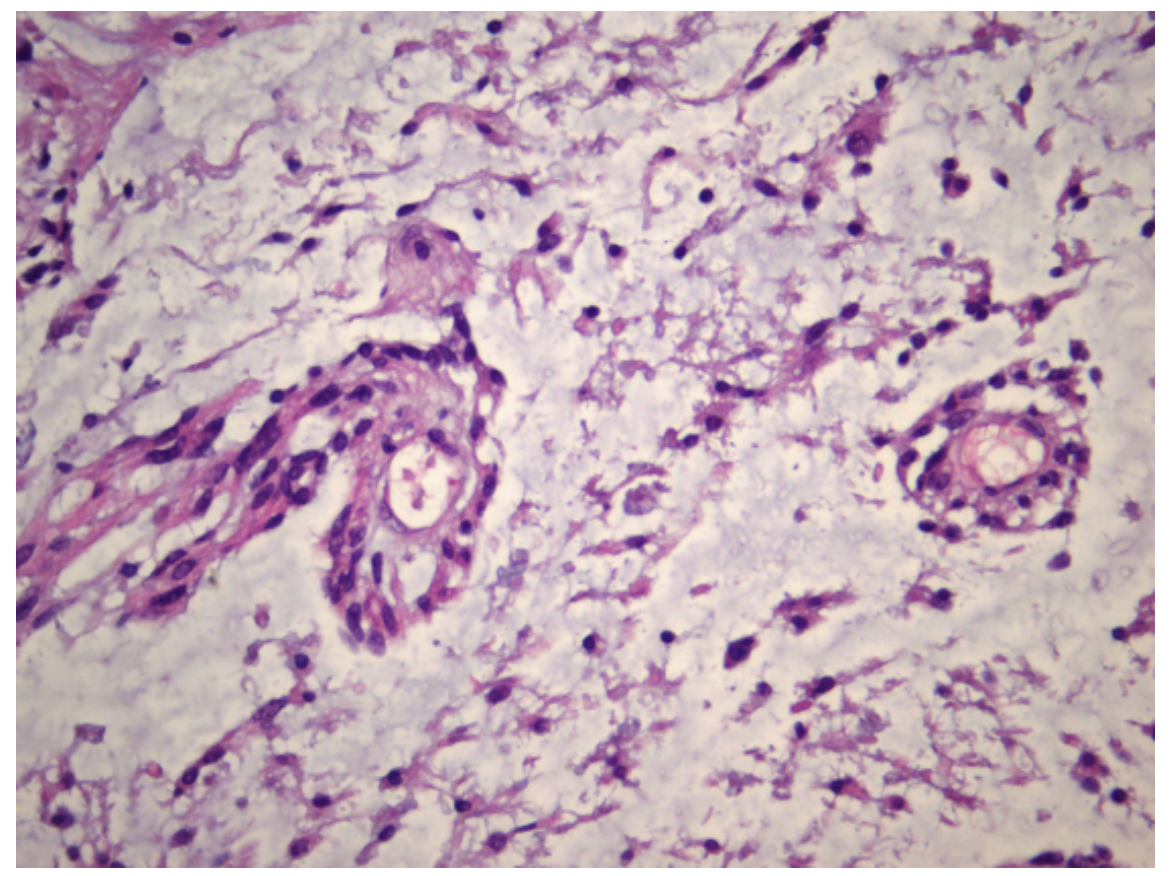



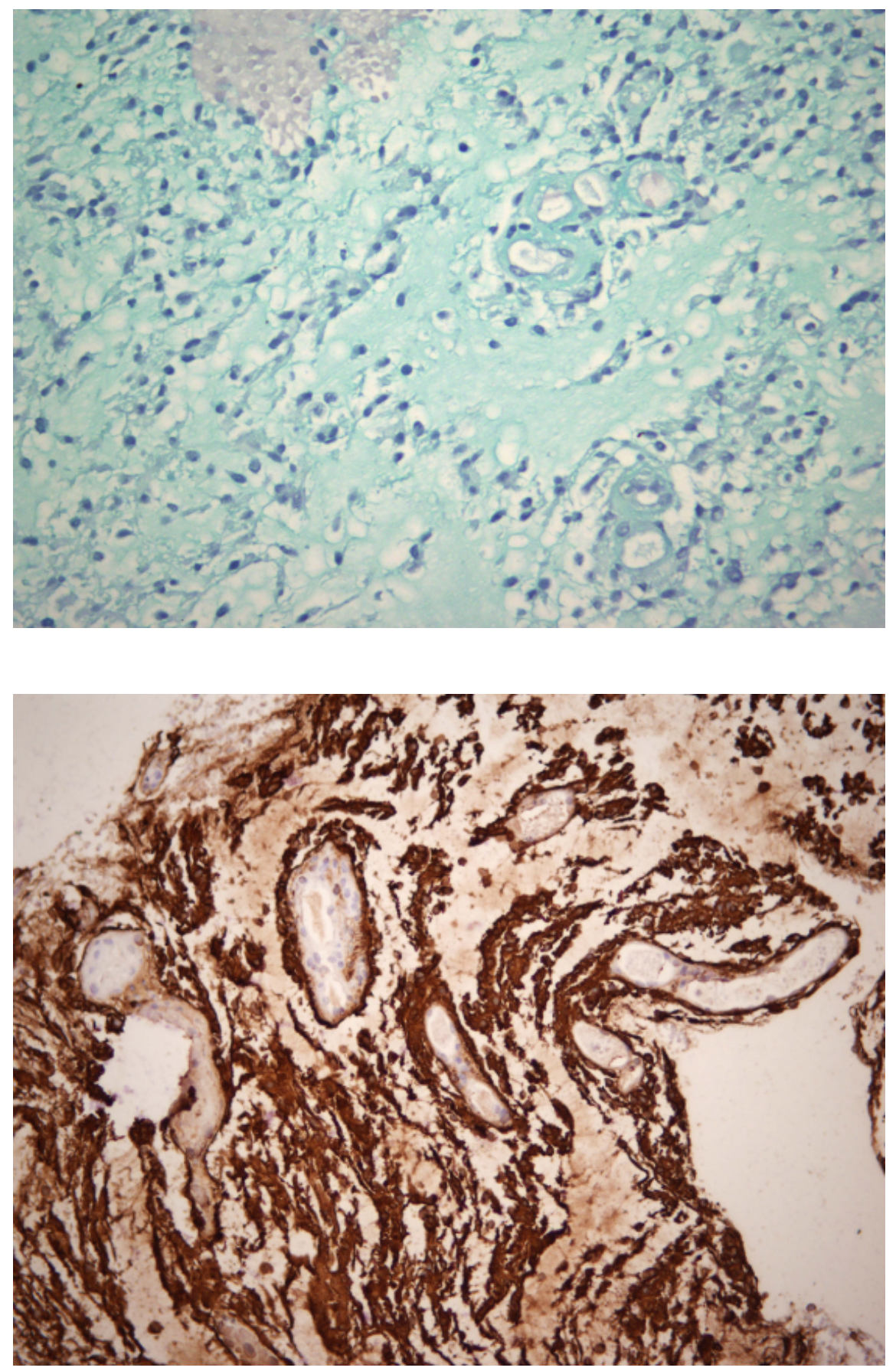

a)

b)

c)

Fig 1. (a) : Tumous cells show tendency for the erivascular arrangement (HE, x400). (b) Myxoid matrix is visualised by Alcian blue his 

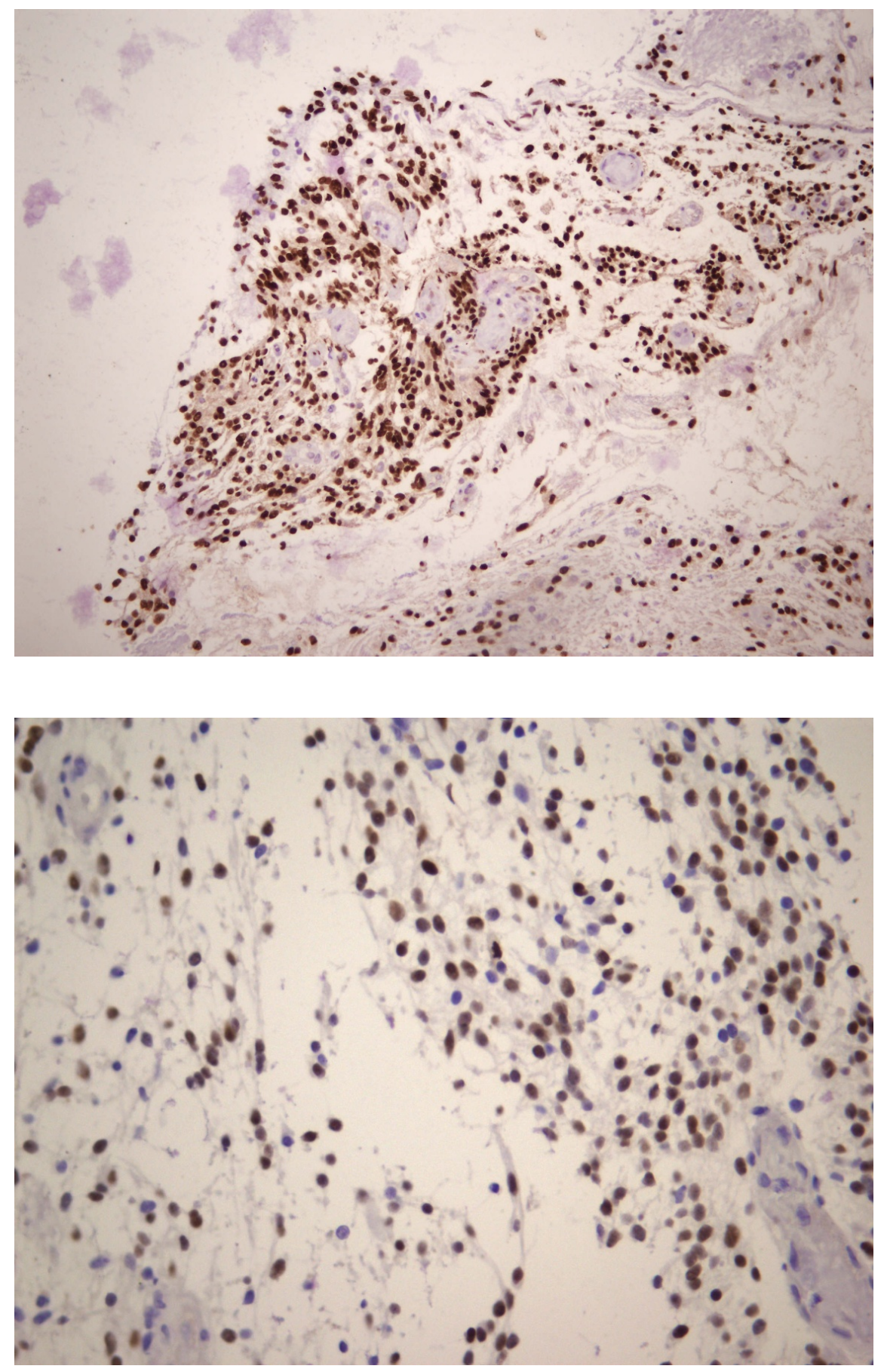

Fig 2. OLIG2 (left, x20) and OSX10 (right, x40) immunopositivity confirms glial origin and excludes the diagnosis of myxopapillary epe

\section{Discussion}

PMA is a relatively rare tumor, it occurs in pediatric groups of patients commonly in the brain [1]. PMA originating in spinal cord is very rare, with over all about 10 reported cases, of which 5 cases involving the thoracic region [Table 1], only one young adult case was reported with an isolated lesion in the thoracic spine without any evidence of other primary systemic or CNS neoplasm $[4,5,6,7,8]$. 
PMA has showed more aggressive behaviour and higher recurrence rate than PA[3]. Radical surgical resection of the tumor showed more favorable survival outcomes within the pediatric population of patients. Restricted surgical resection in the case of spinal PMA was performed in most of reported cases [9].

We report, which what appears to be the second case, of isolated PMA located in the thoracic spine level. MRI findings in our case compare to the only one thoracic adult case reported, MRI has shown similar radiological features in both cases of the thoracic intramedullary PMA. Our lesion on MRI contrast enhanced T2 weighted images showed hyperintense, nonhomogeneous, spindle shape, intramedullary lesion. The T1 weighted images showed hypointense lesion [figure 3]. [5].

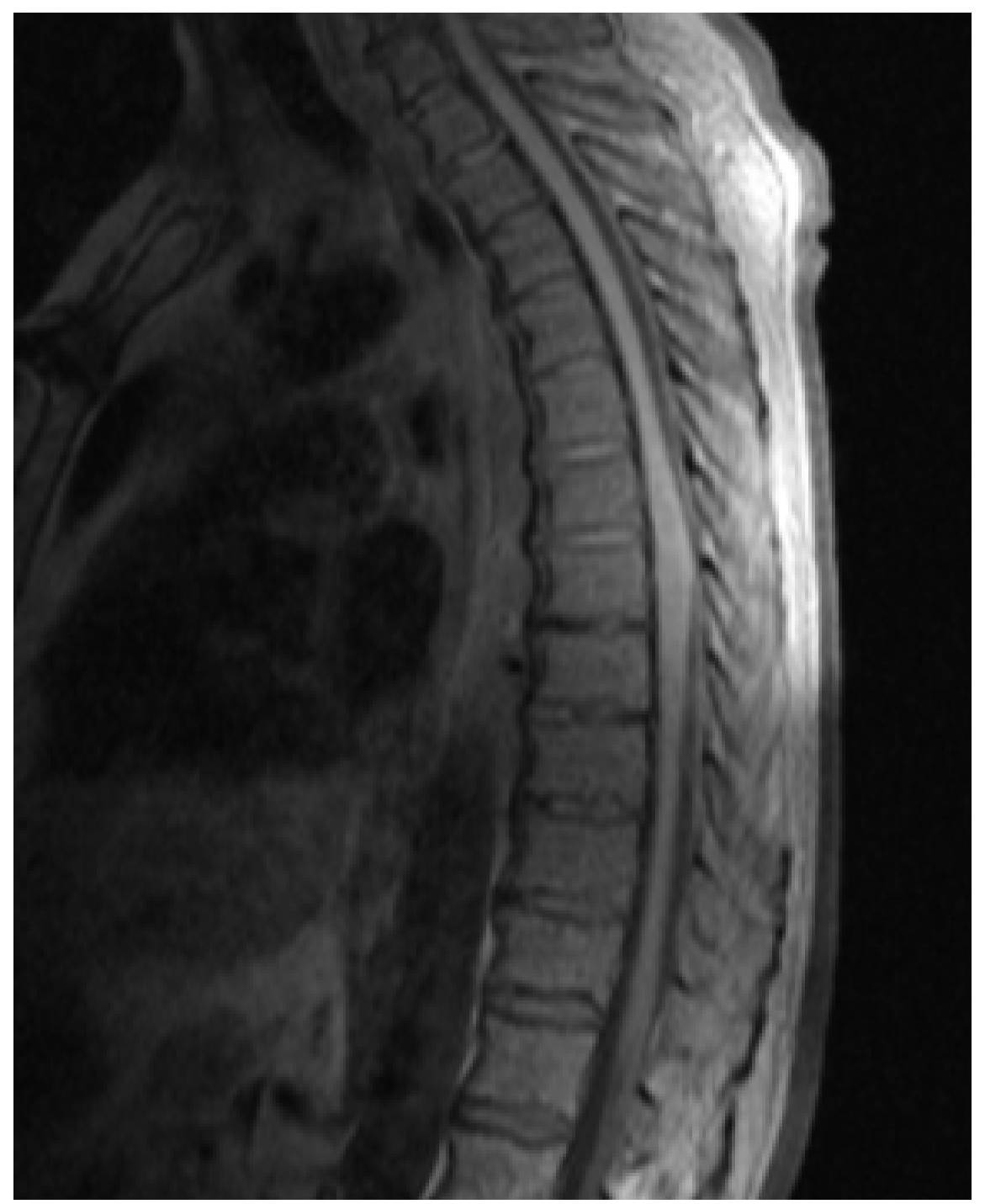




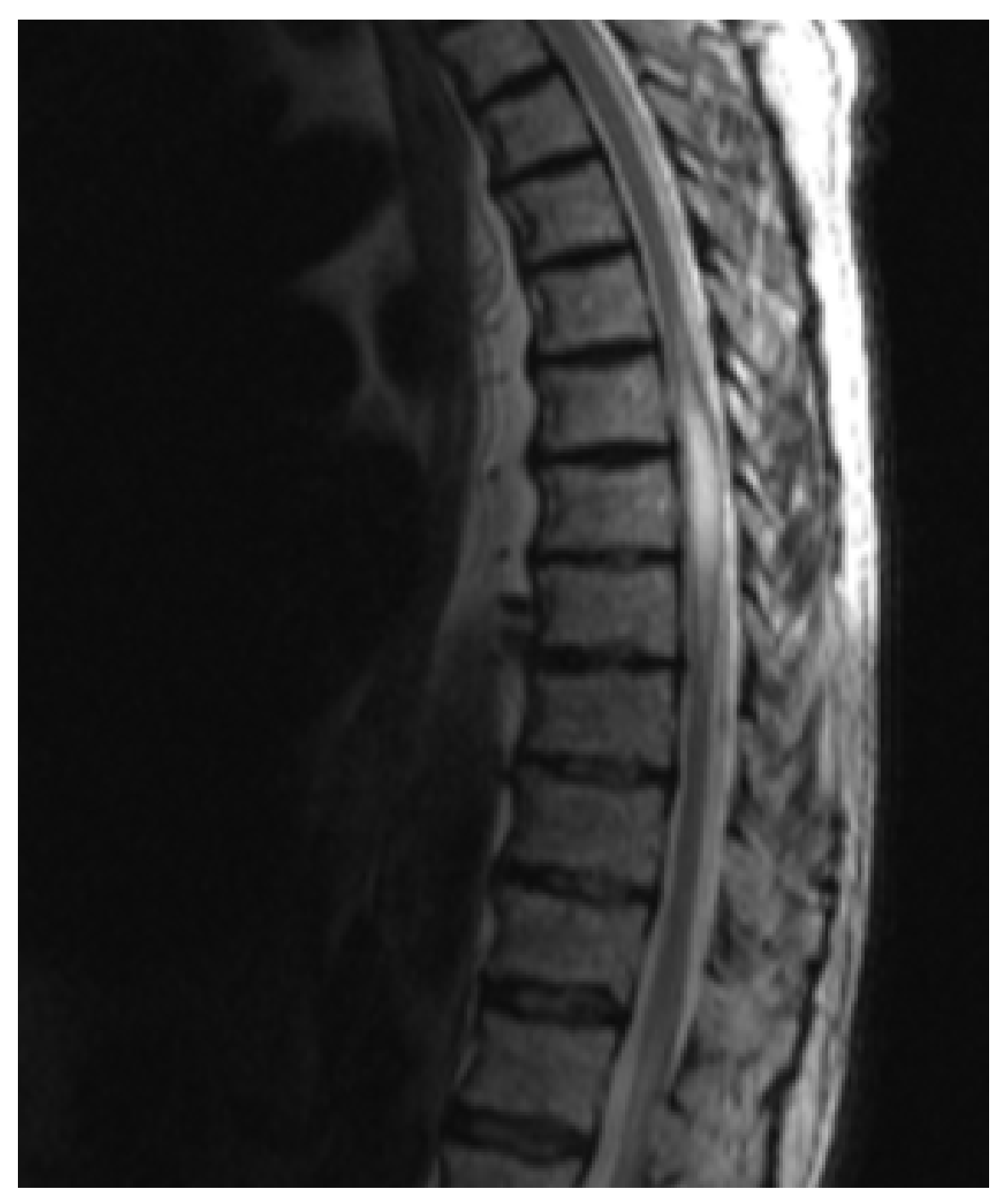

b)

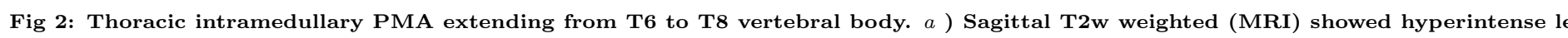

Since PMA is a recently discoverd tumor, reported cases in the literture suggesting difficulty distinguishing radiological imaging features for this extermly rare tumor compare to PA [10]. On the other hand, the histological finding of PMA has dependable difference features compared to PA [3].

\section{Conclusion}

PMA as spinal cord tumor in adults especially over 70 years is extremely rare and lacks treatment guidelines [11]. The oncological treatment is recommended and follow-ups are essential. However, a total surgical removal was only reported in a single case, in addition, the radiological therapy duration and its advantage were not well reported [3].

\section{Reference}

1. Tihan, Tarik et al. "Pediatric Astrocytomas With Monomorphous Pilomyxoid Features And A Less Favorable Outcome". Journal Of Neuropathology \& Experimental Neurology, vol 58, no. 10, 1999, pp. 1061-1068. Oxford University Press (OUP), doi:10.1097/00005072-199910000-00004. 
2. Louis, David N. et al. "The 2007 WHO Classification Of Tumours Of The Central Nervous System". Acta Neuropathologica, vol 114, no. 2, 2007, pp. 97-109. Springer Nature, doi:10.1007/s00401-0070243-4.

3. The 2016 World Health Organization Classification Of Tumors Of The Central Nervous System: A Summary". Acta Neuropathologica, vol 131, no. 6, 2016, pp. 803-820. Springer Science And Business Media LLC, doi:10.1007/s00401-016-1545-1.

4. Dunn-Pirio, Anastasie M. et al. "Single-Agent Carboplatin For A Rare Case Of Pilomyxoid Astrocytoma Of The Spinal Cord In An Adult With Neurofibromatosis Type 1". Case Reports In Oncology, vol 9, no. 3, 2016, pp. 568-573. S. Karger AG, doi:10.1159/000449406.

5. Chaudhuri, Tamojit, and Kamlesh Jadava. "Pilomyxoid Astrocytoma Of The Thoracic Spinal Cord In An Adult: A Case Report And Review Of Literature". Clinical Cancer Investigation Journal, vol 3, no. 4, 2014, p. 329. Medknow, doi:10.4103/2278-0513.134497.

6. Xu, Yulun et al. "Primary Pilomyxoid Astrocytoma Of The Thoracolumbar Spinal Cord In An Adult". Neurology India, vol 61, no. 6, 2013, p. 677. Medknow, doi:10.4103/0028-3886.125376.

7. Bhargava, D. et al. "Occurrence And Distribution Of Pilomyxoid Astrocytoma". British Journal Of Neurosurgery, vol 27, no. 4, 2013, pp. 413-418. Informa UK Limited, doi:10.3109/02688697.2012.752430

8. Sajadi, A. et al. "Pilomyxoid Astrocytoma Of The Spinal Cord In An Adult". Acta Neurochirurgica, vol 150, no. 7, 2008, pp. 729-731. Springer Science And Business Media LLC, doi:10.1007/s00701-008$1605-\mathrm{y}$.

9. Abd-El-Barr, Muhammad M. et al. "Infiltrating Spinal Cord Astrocytomas: Epidemiology, Diagnosis, Treatments And Future Directions". Journal Of Clinical Neuroscience, vol 29, 2016, pp. 15-20. Elsevier BV, doi:10.1016/j.jocn.2015.10.048.

10. Alkonyi, Bálint et al. "Differential Imaging Characteristics And Dissemination Potential Of Pilomyxoid Astrocytomas Versus Pilocytic Astrocytomas". Neuroradiology, vol 57, no. 6, 2015, pp. 625-638. Springer Science And Business Media LLC, doi:10.1007/s00234-015-1498-4.

11. Teng, Yang D. et al. "Spinal Cord Astrocytomas: Progresses In Experimental And Clinical Investigations For Developing Recovery Neurobiology-Based Novel Therapies". Experimental Neurology, vol 311, 2019, pp. 135-147. Elsevier BV, doi:10.1016/j.expneurol.2018.09.010.

Table 1

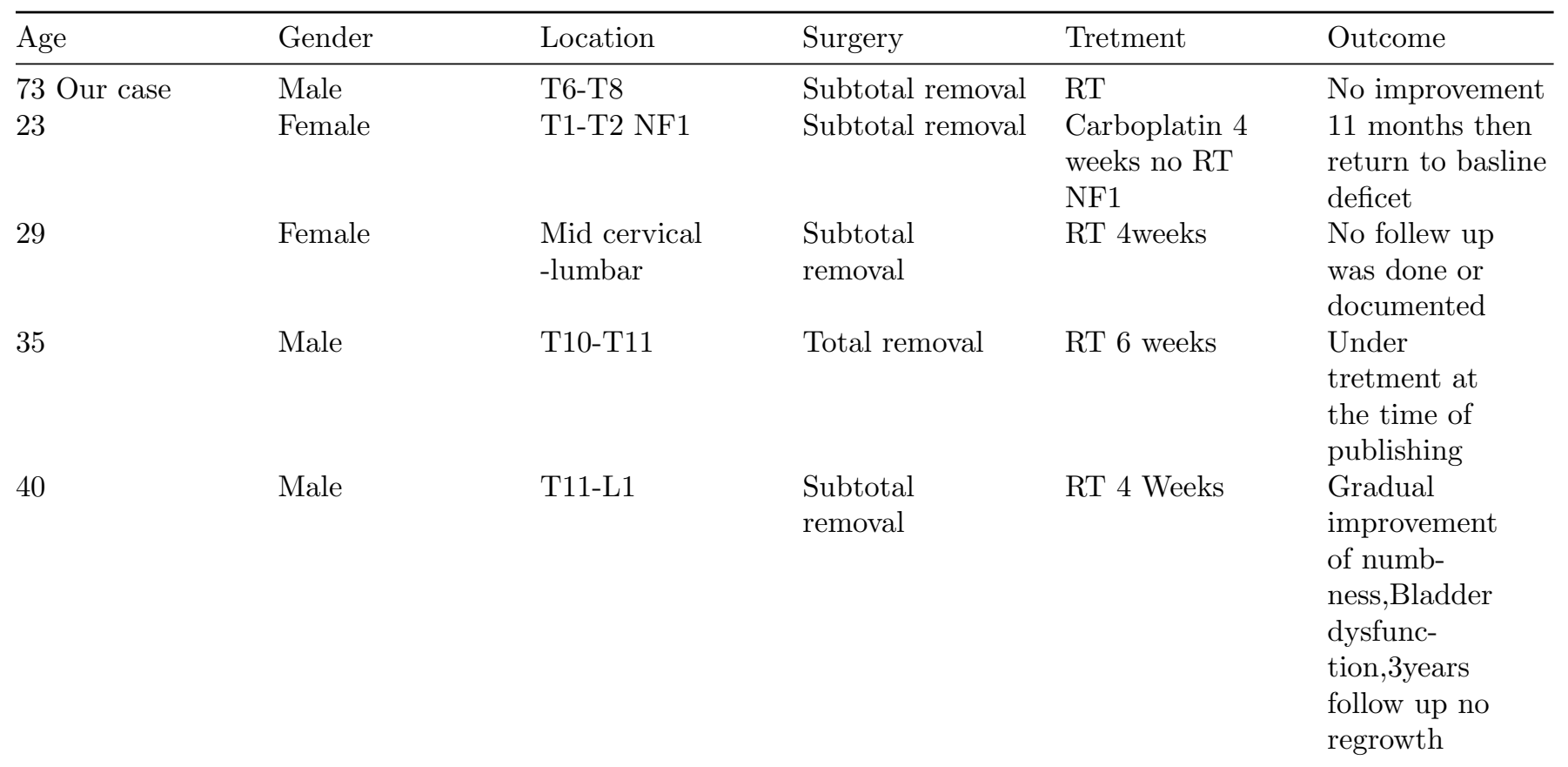




\begin{tabular}{|c|c|c|c|c|c|}
\hline Age & Gender & Location & Surgery & Tretment & Outcome \\
\hline 45 & Female & $\mathrm{C} 1-\mathrm{C} 2$ & $\begin{array}{l}\text { Surgical } \\
\text { biopsy }\end{array}$ & RT 4weeks & $\begin{array}{l}\text { Tetraparasis } \\
\text { then died. } \\
\text { RDS }\end{array}$ \\
\hline
\end{tabular}

RT: Radiotherapy, NF1: Neurofibromatosis type 1, RDS: Respiratory Distress Syndrome. 